\title{
A study on the assistance provided by the family and the community towards well being of elders in the area of the Medical Officer of Health of Kelaniya. DG Gamage ", MW Gunathunga ${ }^{2}$ \\ Introduction
}

Population ageing is an emerging public health issue. The study was carried out to determine the assistance provided by the family and the community towards well being of elders in the $\mathrm{MOH}$ area, Kelaniya. Methodology

A descriptive cross-sectional study was carried out among 576 elders above 60 years using cluster sampling technique. Data collection was done by using interviewer-administered questionnaires and observation check lists. Family assistance was assessed by selected activities in a four point scale categorized into satisfactory level of assistance $=16-24$, moderately satisfactory level of assistance $=9-15$, and unsatisfactory level of assistance $=0-8$.

\section{Results}

The median age of the sample was 78 years, with $58 \%$ females. Satisfactory family assistance was observed in provision of meals $(84 \%)$ and during sickness $(71 \%)$. Assistance provided by the family for social activities was unsatisfactory. A significant difference $(\mathrm{P}<0.005)$ was observed among elders living with their children $(71 \%, 213 / 301)$, compared to those who were not $(28 \%, 77 / 275)$, with regard to wearing clean clothes. There were no differences observed in relation to cleanliness of fingers, toe nails and mouth in both groups. With regard to the assistance provided by the community, only 38\% (111/291) of elders (>70years) received a seat in buses for the specified period of preceded three months. Preferential treatment received only by $21 \%(98 / 467)$ above 60 years in hospitals and by 14\% (53/385) at the banks among elders who required these services.

Awareness on healthy active ageing $(27,5 \%)$ and senior citizen identity card $(113,20 \%)$ were unsatisfactory. The majority complained of lack of community services available for the elderly.

\section{Conclusion}

Assistance provided by the family for social activities was unsatisfactory compared to that for personal/household activities. Assistance provided by the community was unsatisfactory in caring for the elderly. Community awareness programmes and community support services were deficient.

\section{Key words}

elders, well being, family assistance, community assistance

\section{Introduction}

Population ageing is an emerging public health issue, observed both in developed and developing countries. Many successes in the health sector during the last few decades resulted in a rapid demographic change in the $20^{\text {th }}$ century'. During the period 1950-1980 the world elderly population over 65 years increased from $5 \%$ to $10 \%$ and is predicted to increase further up to $20 \%$ by $2025^{1-3}$. In Sri Lanka people over 60 years are expected to increase from 1.92 million (10\%) in year 2000 to 4.45 inillion $(19.7 \%)$ by $2025^{3}$. The life expectancy in males was 70 years and in females was 75 years in 2001 in Sri Lanka. It is estimated that this trend will increase further till 2025 resulting in 75 years in males and 80 years in females ${ }^{4}$.

Maturation of age structure creates new issues to be addressed in the population. A role of the family and the community in caring for the elderly is identified as an essential element in service provision in expecting beneficial social life among elder$1 y^{5}$.

In 1947, the WHO declared health as a state of complete physical, mental and social well being and not merely an absence of disease or infirmity. Health is also described as a "Quality of Life" leading to well being and a process of interaction between the individual and the community ${ }^{6}$.

The family is expected to play a primary role in caring for elders, which would enable them to remain within the family without seeking institutional care. Several societal changes such as the reduction of the extended fitmily system, increased female employment and the reduced number of members in a family contributed to the observed decline in family support'. The informal, traditional support provided by the family in caring elderly needs to be strengthened by providing adequate comprehensive

1. Registrar in Community Medicine, Department of Community Medicine, Faculty of Medicine, University of Colombo.

2. Senior Lecturer in Community Medicine, Faculty of Medicine, University of Colombo. 
elderly care services provided by the community".

The elders who are the recipients of the ultimate effects of services are considered as an adequate source of information regarding their care practices. Therefore, a community study was carried out among elders to determine the assistance provided by the family and the community towards their well being.

\section{Methodology}

A community based descriptive cross-sectional study was carried out among elders above 60 years in the MOH area, Kelaniya. A sample of 576 eligible elders w'as selected using the cluster sampling technique. The sample size was calculated using the appropriate formula for descriptive studies ${ }^{7}$. The study variable considered was the variable contributed for the physical well being of elders which was the level of independence in Activities of Daily Living. Because of high values of independence for the selected variable for physical well being $(74 \%$ \& $89 \%)^{8.9}$ and inadequate sample size in calculation. an approximate value of proportion considered as $50 \%$ in sample size calculation and the total sample multiplied by the cluster factor of 1.5 to adjust for cluster sampling.

Elders who were capable of identifying person, place and time accurately were included in the study as eligible elders and those who were living in their houses alone, with their own family or with relatives and friends are included into the study. Institutionalized elders and elders who had left the area temporarily for a period of more than one month at the time of the study were excluded.

Pre-tested interviewer-administered questionnaires and observation check lists were used as data collection instruments. The assistance provided by the family was assessed hy selected activities in a four- point scale ranging from $0-3$ as always ( 3 points), sometimes ( 2 points), rarely ( 1 point) and never $(0$ point). The score ranges from $0-24$ and categorized into satisfactory assistance (scores 16-24). moderately satisfactory assistance (scores 9.15) and unsatisfactory assistance ( scores 0-8). It , was determined towards routine daily involvements, crisis situations, entertainment opportunities and assistance in religious activities.

Assistance provided by the community was determined by obtaining information on experiences of community assistance towards selected routine social activities for the period of preceded three months and by detecting awareness on welfare measures and services available to them.

Data collection was done by tuained data collectors under the supervision of the principal investigator. Ethical clearance was obtained from the Ethical Review committee in the Faculty of Medicine, University of Colombo. Data analysis was done by using the software programme of Scientific Package for Social Scientists (SPSS).

\section{Results}

The calculated total sample of 576 was recruited from 52 clusters with 12 recruits from one cluster. Only five individuals from three clusters refused to participate and respective clusters were extended further to recruit the relevant number to be satisfied.

\section{Socio-demographic characteristics}

The median age of the sample was 78 years with the age range of $60-96$ years and $58 \%$ were females. The majority of elders $(57 \%)$ were non-income receivers; and a lower percentuge $(14 \%)$ received an income more than Rs. 4000.00 . Only $14 \%$ of the sample was employed.

Table 1-Distribution of elders according to the level the assistance provided by the family

\begin{tabular}{|c|c|c|c|c|c|c|c|c|}
\hline \multirow[t]{3}{*}{ Activity } & \multicolumn{8}{|c|}{ Level of family assistance } \\
\hline & \multicolumn{2}{|c|}{ satisfactory } & \multicolumn{2}{|c|}{$\begin{array}{l}\text { moderately } \\
\text { satisfactory }\end{array}$} & \multicolumn{2}{|c|}{ unsatisfactory } & \multicolumn{2}{|c|}{ Total } \\
\hline & No & $\%$ & No & $\%$ & No & $\%$ & No & $\%$ \\
\hline Assistance during sickness & 408 & 70.8 & 96 & 16.7 & 72 & 12.5 & 576 & 100 \\
\hline Help in washing clothes & 245 & 42.5 & 81 & 14.1 & 250 & 43.4 & 576 & 100 \\
\hline Help in bathing & 140 & 24.3 & 63 & 10.9 & 373 & 64.8 & 576 & 100 \\
\hline Provision of meals & 483 & 83.9 & 58 & 10.1 & 35 & 6.1 & 576 & 100 \\
\hline Provision of money & 199 & 34.5 & 182 & 31.6 & 195 & 33.9 & 576 & 100 \\
\hline Outings for recreation & 143 & 24.8 & 57 & 9.9 & 376 & 65.3 & 576 & 100 \\
\hline Accompany on trips & 164 & 28.5 & 73 & 12.7 & 339 & 58.9 & 576 & 100 \\
\hline
\end{tabular}


Assistance provided by the family

The assistance provided by the family was assessed by selected 8 aspects of care provided by the family during the period of preceded six months towards the well being of the elderly (Table 1). Responses with allocated scores were used to assess the level of the assistance provided by the family. Each level was categorized as satisfactory level of family assistance for the scores of 16-24, moderately satisfactory level of family assistance for the scores of 9-15 and unsatisfactory level of family assistance for the scores of 0-9.

A satisfactory level of family assistance was observed in the provision of meals (84\%) and in assistance in sickness $(70.8 \%)$. There was an unsatisfactory level of family assistance for social activities such as accompanying them out for recreation of less than one day and trips of more than one day.
Significant differences $(p<0.05)$ were observed among elders living with their children compared to those who were not living with their children at household level, with regard to wearing clean clothes and clean, neat hair arrangements. No difference was observed in cleanliness in fingers, toe nails and mouth in both groups (Table 2).

\section{Assistance provided by the community}

With regard to the assistance provided by the community, the experiences of clderly during the period of preceded three months on selected aspects of community care towards their well being was determined (Table 3).

Most elders $(55 \%)$ above 70 years $(n=319)$ were not experienced of receiving a seat in buses. Only a few received priority in hospitals (even at times only $21 \%$ ) and in banks (14\%).

Table 2- Distribution according to observed personnel hygienic measures of elderly, living with own children and others

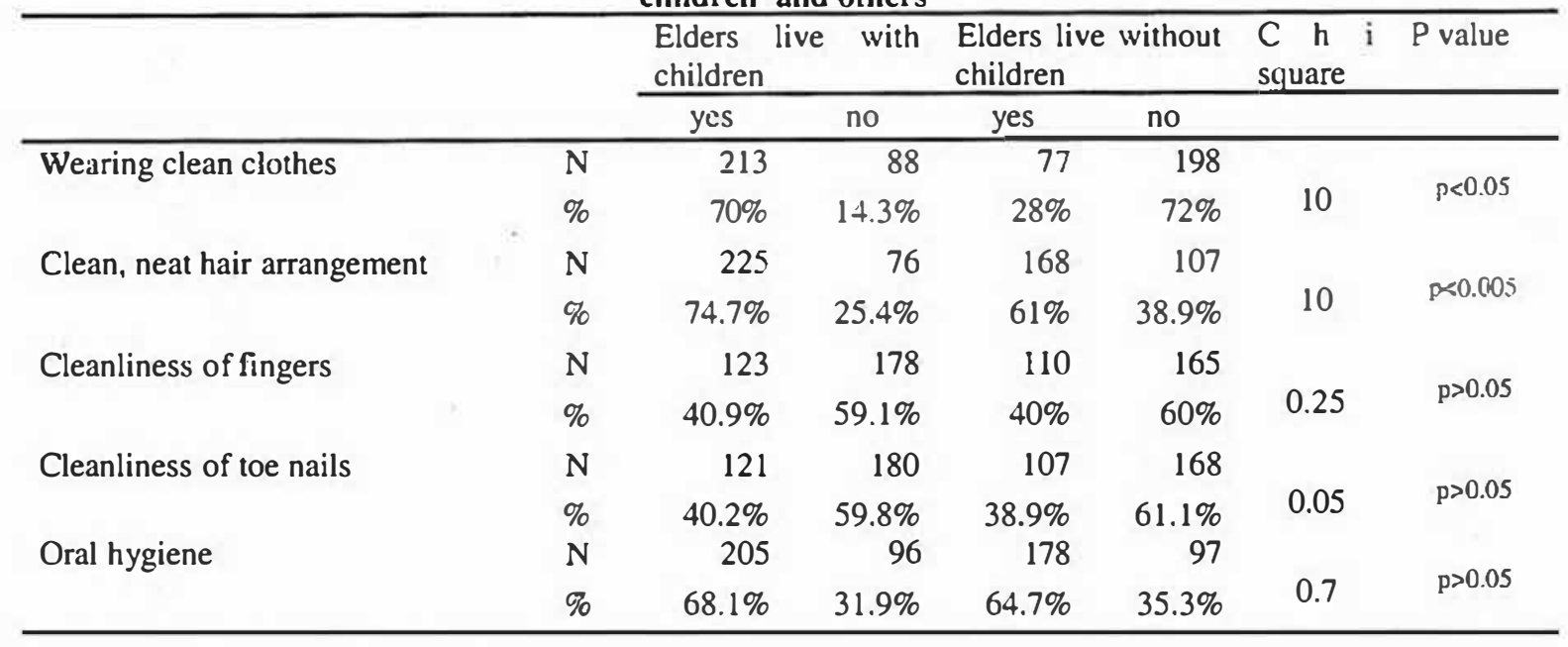

Table 3- Distribution of elders according to the experiences of community assistance

\begin{tabular}{lrrrrr}
\hline \multicolumn{1}{c}{ Event } & \multicolumn{4}{c}{ Experience } \\
\cline { 2 - 6 } & always & sometimes & never & $\begin{array}{c}\text { not in- } \\
\text { volved }\end{array}$ & total \\
\hline Received a seat in travelling by bus & 32 & 90 & 174 & 23 & 319 \\
(above 70 years) & $10 \%$ & $28.2 \%$ & $54.6 \%$ & $7.2 \%$ & $100 \%$ \\
Assistance in crossing a road & 2 & 69 & 107 & 10 & 188 \\
(out of those expressed the requirement) & $1.1 \%$ & $36.7 \%$ & $56.9 \%$ & $5.3 \%$ & $100 \%$ \\
Received priority in a hospital & 10 & 111 & 360 & 95 & 576 \\
& $1.7 \%$ & $19.3 \%$ & $62.5 \%$ & $16.5 \%$ & $100 \%$ \\
Received priority in a bank or in a post office & 3 & 79 & 315 & 179 & 576 \\
& $0.5 \%$ & $13.7 \%$ & $54.7 \%$ & $31.1 \%$ & $100 \%$ \\
\hline
\end{tabular}


The available welfare measures and user friendliness of scrvices available for the elderly were deficient. Only 20\% (113) knew about how to get a senior citizen identity card. Few elders $(<20 \%)$ were aware that there were privileges and bencfits available for elders at government paying wards, pharmacies and banks.

The $\mathrm{MOH}$ area Kelaniya was included in the elderly care programme introduced by the Ministry of Health. The awareness on healthy active ageing introduced to the community through the $\mathrm{MOH}$ office was inadequate (5\%) among elders. A total of only $13 \%$ knew about the special elderly care clinic conducted by the $\mathrm{MOH}$ office in the area.

\section{Discussion}

A descriptive cross-sectional study was carried out in the scmi-urban arca of Kelaniya which is representative of both urban and rural areas. A comparison study of urban, rural and estate would have been more beneficial in finding out differences in levels of assistance provided by the tamily and the community ensuring well being of elders. However, a cross-sectional study was considered adequate in determining the level of assistance provided by the family and the community for the well being of elders.

Considering different levels of literacy and the possibility of family influence in manipulation of responses, interviewer-administered questionnaires (IAQ) were used. IAQ was expected to reduce the non-response rate as well. The information collected from elders themselves was considered more valid than the information collected from their care givers.

Compared to a study carried out in the same district about a decade ago ${ }^{7}$. the present study revealed higher employment rates. The lower income levels were contributed to the poverty and to the economic dependency of elders.

The higher frequencies observed in the satisfactory level of the family assistance for the provision of meals and in assistance in sickness revealed that family involvement in some aspects of providing basic requirements and in crisis situations were satisfactory. A study done in Sri Lanka including urban, rural and estate sectors showed a satisfactory level of assistance from the family on the clderly (79\%) in household work. The response in rural areas $(84 \%)$ was better than in urban arcas $(63 \%)$. The reasons were not evaluated in the study $y^{5}$.
A significantly higher level of family assistance was observed for providing clothes and ensuring clean. neat hair arrangements in elders living with their own children (Table 2). These two aspects of care are considered as factors contributing most to external appearance of them. The family involvement in accompanying elders in both short term and long term recreational activities were not satisfactory compared to household level basic essential care practices. This reveals that majority of families are ready to provide only the very basic care for elders rather than a comprehensive care.

A previous study done in Sri Lanka revealed that journeys among elders within the home country were popular only among $6.7 \%$. Only $9 \%$ were involved in outings for entertainments ${ }^{5}$. The reasons for inadequate family assistance or their less involvement in such activities in this regard needs to be evaluated in further studies.

The most assistance required activities of crossing a main road and receiving a seat while travelling in public transport showed very poor community care towards elderly. Majority of elders did not get priority based treatment at hospitals. The prevailing system in hospitals for treatment priority is still based on priority numbers. Unless such system is changed, the possibility of elders to wait in long queues for treatment would remain same.

A majority revealed the lack of awareness regarding elderly care services available for them in Sri Lanka. The service of priority for senior citizens at banks and in post offices has been already declared according to the information received from the Elderly Secretariat at Social Services department. Such services should be available for them without their demand. In the study only a minority of elders (14.2\%) expcrienced these services.

The lack of awareness of the majority of elders in how to obtain the senior citizens identity card and benefits in getting it should be addressed through community care programmes. An effective method should be developed to improve awareness of welfare facilities available for elderly and which would enable them to use such services for the benefit of them.

\section{Conclusion}

The assistance provided by the family for care in social activities of elderly was unsatisfactory compared to the assistance provided for personal household level basic care practices. 
There is a lack of awareness among the elderly about community care benefits available to them.

\section{Acknowledgement}

Authors wish to thank the Provincial Director of Health Services-Western Province, the Deputy Provincial Director of Health Services- Gampaha District. the Medical Officer of Health - Kelaniya and all the elders who participated in the study.

\section{References}

1. Perera PAD. Emerging issues in population ageing in Sri Lanka. Asian Population studics series . United Nations. 1989.

2. WHO. Elders in South East Asia. Health Situation in South East Asia. 2003; 51-53.

3. Abeykoon ATPL. Ageing and health sector in Sri Lanka. Ceylon Medical Journal. 2000; 45: 52-54.

4. Ministry of Health. Annual Health Bulletin. Department of Health services, Sri Lanka. 2003.

5. Hurley J. The Challenge of Ageing- common problems. Melboume: Churchill Livingstone: 1992.

6. Gee EM. Misconception and misapprehension about people ageing. International Journal of Epidemiology. 2000;31:750-3.

7. Lwanga L. Sample size determination in health studies. 1991.

8. Lokubalasooriya SA. Physical and Mental health status of the elderly in $\mathrm{MOH}$ area Ragama, Dissertation. PGIM. University of Colombo 1994.

9. Balasooriya A. Factors influencing the utilization of health services by elders in DDHS arca Beruwala, Dissertation.PGIM. University of Colombo 1995. 